\title{
Avaliação dos efeitos da adição de trub na fermentação de uma cerveja do tipo Pilsen
}

Evaluation of the effects of trub addition in the fermentation of a Pilsen beer

\author{
1 Sávio de Meneses Leite Asevedo saviomeneses@icloud.com \\ 1 Camilla Rocha de Oliveira Fontoura \\ ' Lígia Marcondes Rodrigues dos Santos
}

1 Universidade de Vassouras

\section{Resumo}

A cerveja é uma bebida alcoólica produzida através de um processo de fabricação dividido em 3 etapas: produção do mosto, fermentação/maturação e finalização. É na produção do mosto, mais especificamente na etapa de fervura, onde ocorre a formação do trub quente, um dos resíduos sólidos gerados no processo cervejeiro e no qual possui potenciais efeitos prejudiciais, no que diz respeito à eficiência da fermentação e uma boa qualidade final da cerveja. Neste estudo, foram analisados o teor alcoólico, viabilidade e crescimento celular, bem como o decaimento de extrato na fermentação de uma cerveja do tipo Pilsen, a partir de variadas concentrações de trub. Com base nas análises, observou-se um aumento no teor alcoólico, tendo para a concentração de $4 \mathrm{~g} / \mathrm{L}$ de trub atingido o valor máximo de $6,95 \%(\mathrm{v} / \mathrm{v})$, ultrapassando o grau alcoólico teórico de $6,83 \%$. O crescimento celular também alcançou pontos elevados em relação ao controle, tendo um aumento de $36 \%$ a $40 \%$ para as concentrações utilizadas de 2 e $4 \mathrm{~g} / \mathrm{L}$, respectivamente. Dessa forma, observou-se um aumento nos valores apresentados através das análises, conforme o aumento na concentração de trub, vindo a demonstrar um bom desempenho da sua utilização na fermentação. Cabe a realização de outros estudos sobre seus efeitos negativos, especialmente a análise sensorial da cerveja resultante, como também a introdução de maiores concentrações de trub, a fim de realizar um acompanhamento, tendo em vista seu potencial eficaz na fermentação.

\section{Palavra-chave}

Fermentação. Trub. Leveduras.

\begin{abstract}
Beer is an alcoholic beverage produced through a manufacturing process divided into 3 steps: wort production, fermentation/brewing and finishing. It is in the wort production, more specifically in the boiling stage, where hot trub formation occurs, one of the solid residues generated in the brewing process with potential detrimental effects related to fermentation efficiency and a good final beer quality. In this study were analysed alcohol content, viability and cell growth as well as the decay of the extract in the fermentation of a Pilsen beer from different trub concentrations. Based on the analyses, an increase in alcohol content was observed, with a concentration of $4 \mathrm{~g} / \mathrm{L}$ of trub reaching a maximum value of $6.95 \%$ $(\mathrm{v} / \mathrm{v})$, exceeding the theoretical alcohol level of $6.83 \%$. Cell growth also reached high points related to control sample, increasing from $36 \%$ to $40 \%$ for 2 and $4 \mathrm{~g} / \mathrm{L}$ concentrations, respectively. Thus, there was an increase in the values presented by the analysis, as the increase of trub concentration, demonstrating a good performance of its use in fermentation. Further studies on its negative effects are required, especially the sensory analysis of the resulting beer, as well as the introduction of higher trub concentrations in order to monitor its effective fermentative potential.
\end{abstract}

\section{Keywords}

Fermentation. Trub. Yeast.

\section{Como você deve citar?}

ASEVEDO, Sávio de Meneses Leite Asevedo; FONTOURA, Camilla Rocha de Oliveira; SANTOS, Lígia Marcondes Rodrigues dos Santos. Avaliação dos efeitos da adição de trub na fermentação de uma cerveja do tipo Pilsen. Cadernos UniFOA, Volta Redonda, n. 42, p. 23-32, abril, 2020. 


\section{INTRODUÇÃO}

A cerveja é uma bebida alcoólica fermentada presente nas tradições humanas desde a Antiguidade. Sua produção e consumo datam de 6000 A.C. Sua fabricação teve início na Mesopotâmia, região do Oriente Médio, que possui os registros mais antigos sobre a prática de produção da bebida (GIORGI \& JÚNIOR, 2016).

No decreto $n^{\circ}$ 9.902, de 8 de julho de 2019, a legislação brasileira denomina cerveja como a bebida resultante da fermentação, a partir da levedura cervejeira, do mosto de malte de cevada ou de extrato de malte, submetido previamente a um processo de cocção adicionado de lúpulo ou extrato de lúpulo, hipótese em que uma parte do malte de cevada ou do extrato de malte poderá ser substituída parcialmente por adjunto cervejeiro (BRASIL, 2019).

Pode-se definir como simples o processo de fabricação de cerveja, dividido em 3 etapas fundamentais: produção do mosto (brassagem), fermentação/maturação e finalização (LAURINTINO et al., 2016). A primeira etapa envolve desde a moagem do malte até a clarificação do mosto e sua fervura. Já a segunda, é subdividida em fermentação e maturação. Por fim, o acabamento envolve filtração, carbonatação, pasteurização, envase, dentre outras operações que podem ser realizadas.

É na produção do mosto, mais especificamente na etapa de fervura, onde ocorre a formação do trub quente, um dos resíduos sólidos gerados no processo cervejeiro, como apresentado pela Figura 1. Ele se caracteriza como um aglomerado de proteínas insolúveis, carboidratos complexos, lipídios, taninos, minerais e componentes do lúpulo. 0 trub possui em sua composição de $40-70 \%$ de proteínas, $7-32 \%$ de substâncias amargas, 20 - 30\% de substâncias orgânicas, como polifenóis e 5\% de cinzas (KÜHBECK et al., 2006). Ele é constituído de partículas que variam de tamanho entre 30 a 80 microns. A quantidade formada varia entre 2 a $4 \mathrm{~g} / \mathrm{L}$ em peso úmido (80 - 85\% água) dependendo de vários fatores (BARCHET, 1993).

Figura 1 - Ilustração fotográfica do trub quente

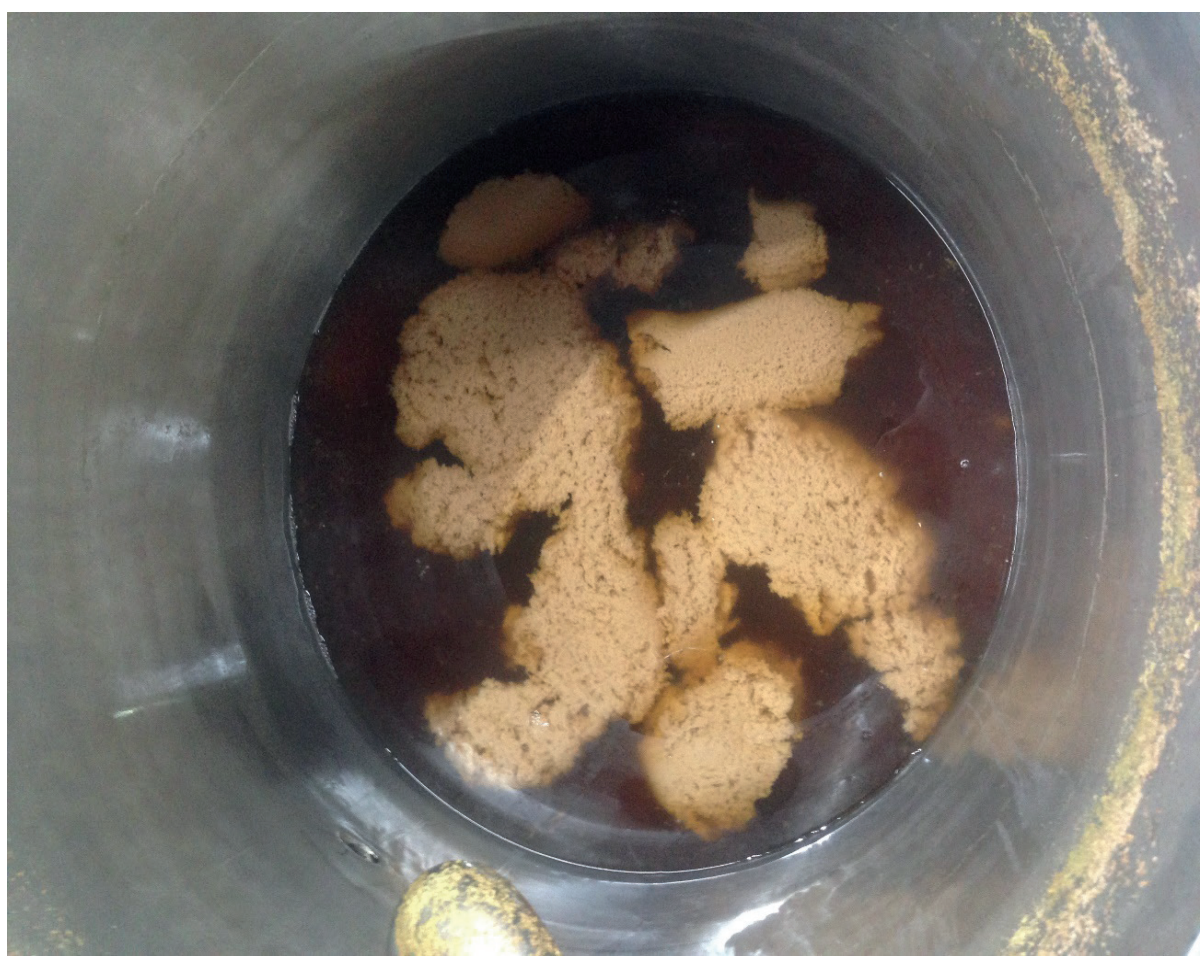

Fonte: os autores. 
Alguns fatores são levados em consideração para a ocorrência de formação do trub durante a fervura do mosto. De acordo com Kühbeck et al. (2006), quanto maior for o tempo em ebulição, maior será a formação de trub quente. Uma alta transferência de calor também favorece sua formação. 0 movimento durante a fervura do mosto também contribui para seu desenvolvimento, sendo que, quanto maior a velocidade de agitação, maior será a formação de trub quente e vice-versa.

Tendo sua formação no tanque de fervura e, portanto, estando em contato direto com o mosto, uma das formas de separação mais conhecidas se dá por um processo denominado whirpool, no qual a movimentação, agindo através da força centrifuga, faz com que as partículas entrem em atrito com a borda do tanque, reduzindo sua velocidade, decantando no fundo do tanque e se aglomerando no centro. A Figura 2 ilustra a dinâmica de movimentação do mosto e das partículas sólidas no whirlpool (MILAGRES, 2019).

Figura 2 - Movimentação exercida pelo mosto e as partículas sólidas no whirpool

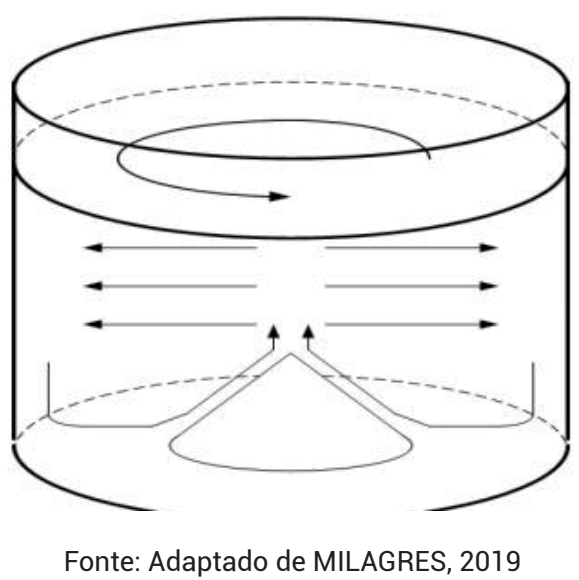

O trub quente tem sido objeto de muitas discussões e publicações entre os fabricantes de cerveja e sua completa remoção dita crucial no que se refere à eficiência da fermentação e uma boa qualidade final do produto. Entre os potenciais efeitos prejudiciais que o trub quente pode causar, está no envolvimento da parede celular da levedura, impedindo o transporte de substâncias para dentro e fora da célula, o que pode levar a problemas de fermentação como um todo, assim como na estabilização da espuma, baixa estabilidade no sabor e intenso amargor no paladar (BARCHET, 1993).

O trabalho em questão teve como objetivo realizar uma avaliação dos parâmetros, teor alcóolico, viabilidade e crescimento celular, bem como o decaimento de extrato sobre a fermentação de uma cerveja do tipo Pilsen, na qual foi adicionado trub em duas concentrações diferentes e comparadas com uma cerveja controle, sem adição de trub.

\section{PROCEDIMENTO EXPERIMENTAL}

\subsection{Produção da cerveja para obtenção do mosto cervejeiro}

O processo de produção do mosto se deu na planta piloto da Cervejaria Escola da Universidade de Vassouras (Vassouras/RJ), utilizando-se receita de uma cerveja tipo Pilsen, expressa na Tabela 1. 
Tabela 1 - Receita utilizada neste estudo para uma cerveja tipo Pilsen

\begin{tabular}{cc}
\hline INGREDIENTES & QUANTIDADES \\
\hline Malte & $16 \mathrm{~kg}$ \\
\hline Lúpulo & $19 \mathrm{~g}$ \\
\hline Água & $56 \mathrm{~L}$ (Mostura) \\
\hline & 39 L (Clarificação) \\
\hline
\end{tabular}

Fonte: os autores.

Na Tabela 2, demonstram-se os valores de temperatura e tempo, para cada etapa do processo.

Tabela 2 - Dados de temperatura e tempo utilizados neste estudo para a produção da cerveja tipo Pilsen

\begin{tabular}{ccc}
\hline ETAPA & TEMPERATURA $\left({ }^{\circ} \mathrm{C}\right)$ & TEMPO \\
\hline Mosturação & 66 & 30 a 180 min \\
\hline Clarificação & 78 a 80 & 60 a 120 min \\
\hline Fervura & 100 & 60 a 90 min \\
\hline Resfriamento & 12 a 18 & $1 \mathrm{~h}$ \\
\hline Fermentação & 11 a 20 & 3 a 7 dias \\
\hline
\end{tabular}

Fonte: os autores.

A partir da obtenção do mosto, as amostras foram coletadas em 6 recipientes de $15 \mathrm{~L}$, devidamente identificados e higienizados. Foram utilizadas concentrações de 0 (controle), 2 e $4 \mathrm{~g} / \mathrm{L}$ de trub, sendo, para as concentrações de 0 e $2 \mathrm{~g} / \mathrm{L}$ coletados, $10 \mathrm{~L}$ de mosto e, para a concentração de $4 \mathrm{~g} / \mathrm{L}$, $3 \mathrm{~L}$ de mosto. As fermentações foram conduzidas em duplicata.

Após a retirada dos volumes para as fermentações, o mosto residual contendo o trub foi recolhido em um balão, homogeneizado e transferido $10 \mathrm{~mL}$ para um tubo de centrífuga graduado. Também foi centrifugado e, dessa forma, obteve-se o quantitativo de trub em $10 \mathrm{~mL}$ de solução.

A inoculação do fermento foi realizada utilizando-se células de leveduras Nottigham da marca Lallemand de alta fermentação com dosagem de $0,5 \mathrm{~g} / \mathrm{L}$. As amostras, então, foram levadas à fermentação sob temperatura entre $18-22^{\circ} \mathrm{C}$.

\subsection{Viabilidade de leveduras e Crescimento celular}

A contagem de células foi realizada em câmara de Neubauer e, para isso, foram preparadas diluições de 10, 40 e 100 vezes, de acordo com as concentrações apresentadas pelas amostras. Foram utilizadas 2 gotas de corante azul de metileno para promover a diferenciação entre as células viáveis e não viáveis. A câmara foi devidamente esterilizada, utilizando-se água e álcool $70 \%$ e a lamínula foi fixada.

Em seguida, foi pipetado $0,5 \mathrm{~mL}$ da amostra diluída na borda da lamínula, de forma que o conteúdo preencheu totalmente o volume da câmara, mas sem deixar vazar a amostra ou cair sobre a lamínula. As células ficaram em repouso por $2 \mathrm{~min}$, para que ocorresse a sua sedimentação. Foi utilizada a objetiva de 40 vezes para as análises.

Devido à alta probabilidade de erro por parte do técnico na realização da contagem das células, diferentes técnicas são apresentadas por alguns laboratórios. Neste estudo, foi utilizado o método de 
contagem de células com auxílio do corante azul de metileno, utilizando-se a Câmara de Neubauer. (DAS NEVES, 2003).

A equação para o cálculo do número de células por volume é apresentada a seguir:

$$
n^{\circ} \text { de } \frac{\text { células }}{m L}=\frac{n^{\circ} \text { total de células }}{n^{\circ} \text { de quadrantes contados }} x \text { fator de diluição } x 10000
$$

\subsection{Decaimento de extrato}

Para obtenção da medida do extrato, que corresponde a porcentagem em peso de sólidos solúveis em solução, foram obtidas as densidades do mosto antes, durante e pós fermentação, sendo estas definidas como: OG (Original gravity) é a densidade inicial relativa à quantidade de substâncias fermentescíveis e não fermentescíveis logo antes do início da fermentação, ou seja, trará uma ideia do potencial percentual alcoólico para a cerveja em questão; SG (specific gravity) é a densidade durante a fermentação, que relaciona a densidade dos açúcares fermentescíveis e a densidade da água; e o FG (final gravity) é a densidade final medida após a fermentação determinada por sua não alteração por mais de 2 dias (GOMES, 2018).

A medida para o OG foi realizada utilizando-se de um refratômetro portátil da marca KASVI ( ${ }^{\circ}$ Brix) a partir de uma gota do mosto resfriado a, aproximadamente, $20^{\circ} \mathrm{C}$. 0 decaimento de extrato (SG) foi realizado utilizando-se um densímetro alcoólico, a partir da coleta de $100 \mathrm{~mL}$ de amostra transferida para uma proveta de mesmo volume, que foi realizado para se obter o FG, determinando assim o final da fermentação.

\subsection{Teor alcoólico}

A análise de teor alcoólico se deu utilizando-se o método analítico de álcool em volume a $20^{\circ} \mathrm{C}$ do Instituto Adolf Lutz. O método é utilizado para determinar o teor de álcool em volume em amostras de cerveja a partir de uma tabela de conversão de densidade relativa a $20^{\circ} \mathrm{C} / 20^{\circ} \mathrm{C}$ (INSTITUTO ADOLF LUTZ , 2008).

Foi preparado um conjunto de destilação simples, contendo garras, suporte universal, manta aquecedora, balão volumétrico de $250 \mathrm{~mL}$ de fundo chato e redondo, termômetro, mangueiras, condensador, juntas e banho de gelo.

As análises foram realizadas em amostras descarbonatadas. Para isso, foi transferida uma alíquota para um recipiente plástico com tampa e promoveu-se agitação para a retirada do gás carbônico com aberturas frequentes para a expulsão do gás. A temperatura da cerveja deve ser mantida em torno de $20-25^{\circ} \mathrm{C}$.

Foram transferidos $100 \mathrm{~mL}$ da amostra descarbonatada para o balão de fundo redondo acoplado ao sistema. Para prevenir a formação de espuma, utilizou-se 2 gotas de antiespumante. A destilação ocorreu durante $1 \mathrm{~h} 30 \mathrm{~min}$, tempo tido como hábil para a coleta do destilado. A amostra foi recolhida em um balão de fundo chato em banho de gelo, transferido para um balão volumétrico de $100 \mathrm{~mL}$, tendo seu volume completo com água e homogeneizado. 
Após o preparo da solução, a amostra foi introduzida em uma proveta de $100 \mathrm{~mL}$. A densidade relativa da solução foi determinada através de um densímetro e o teor de álcool foi obtido através da tabela de conversão, segundo o método do Instituto Adolfo Lutz (2008).

Ao final, foi realizado o cálculo de gradação alcóolica (\% ABV), a fim de se obter o teor alcoólico téorico ao final da fermentação, levando-se em consideração o extrato inicial (OG) e final (FG), segundo a equação de Papazian (2003).

\section{$3 \quad$ RESULTADOS E DISCUSSÕES}

As fermentações tiveram duração de 5 dias, sob controle da temperatura em torno de $18-22^{\circ} \mathrm{C}$,

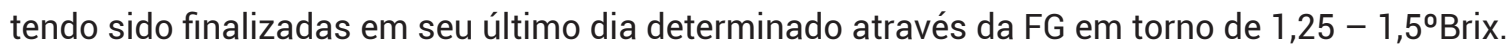

Em relação ao decaimento de extrato, foi possível observar uma similaridade no comportamento apresentado para as concentrações de 2 e 4 g/L em relação ao controle (Gráfico 1).

Gráfico 1 - Decaimento de extrato: Valores de extrato vs. tempo de fermentação para as concentrações de trub de $0 \mathrm{~g} / \mathrm{L}(\bullet), 2 \mathrm{~g} / \mathrm{L}(\bullet)$ e $4 \mathrm{~g} / \mathrm{L}(\mathbf{\Delta})$. Extrato inicial de todas as amostras: $14,5^{\circ}$ Brix; extrato final: $1,25^{\circ} \operatorname{Brix}(0$ e $2 \mathrm{~g} / \mathrm{L})$ e $1,5^{\circ} \operatorname{Brix}(4 \mathrm{~g} / \mathrm{L})$.

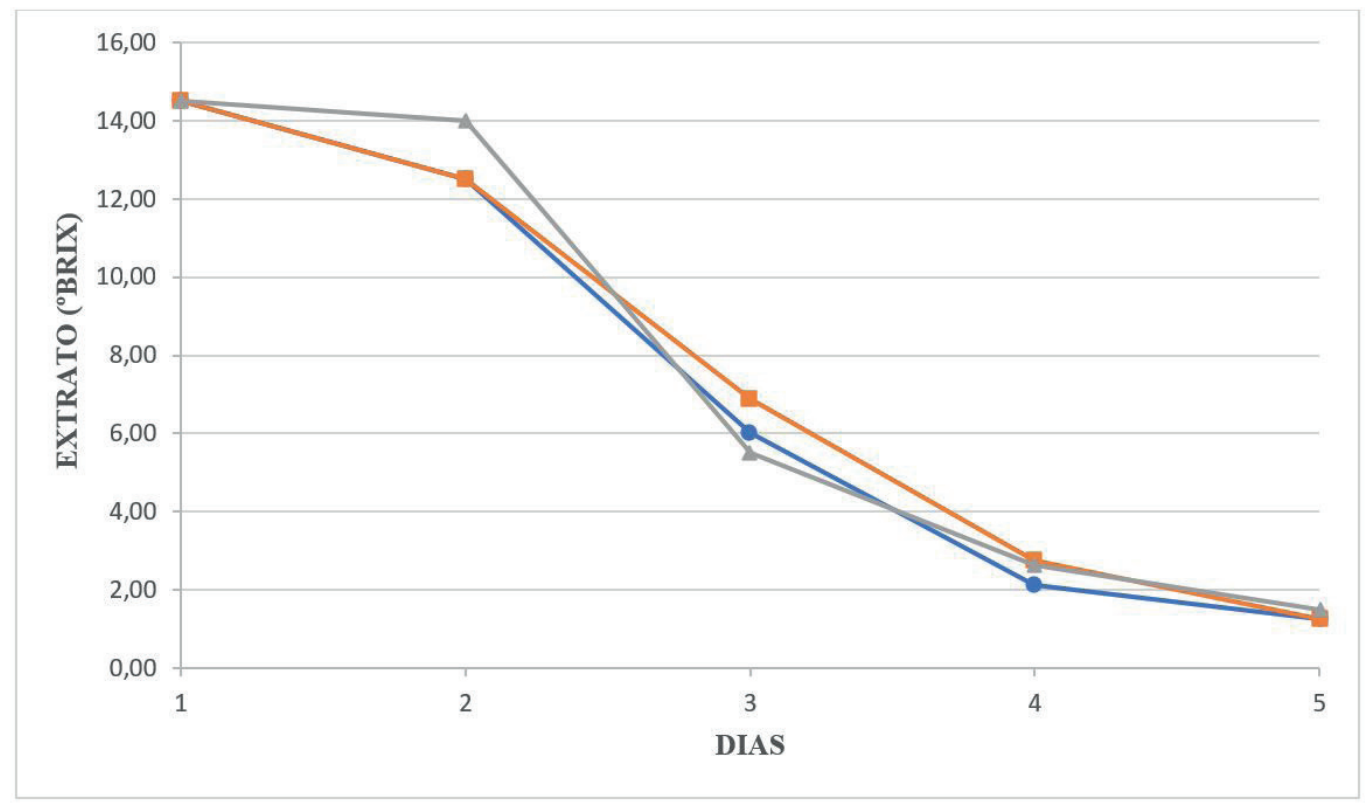

Fonte: os autores.

Ao final da fermentação, observou-se uma proximidade entre os pontos finais, sendo de 1,25 ${ }^{\circ}$ Brix para o controle e a concentração de $2 \mathrm{~g} / \mathrm{L}$ e 1,50 ${ }^{\circ}$ Brix para a concentração de $4 \mathrm{~g} / \mathrm{L}$. Assim, apesar da presença do trub, os extratos das amostras chegaram ao mesmo patamar, o que é um indicativo de que as duas concentrações estudadas não foram prejudiciais nesse parâmetro. 
Gráfico 2 - Concentração de células de leveduras suspensas no mosto fermentado vs. tempo de

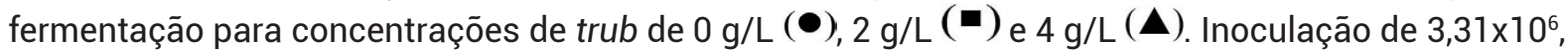
$3,46 \times 10^{6}$ e $4,19 \times 10^{6}$ células $/ \mathrm{mL}$ iniciais, respectivamente; crescimento de $36 \%(2 \mathrm{~g} / \mathrm{L})$ e $40 \%$ (4 g/L) frente ao controle $(0 \mathrm{~g} / \mathrm{L})$.

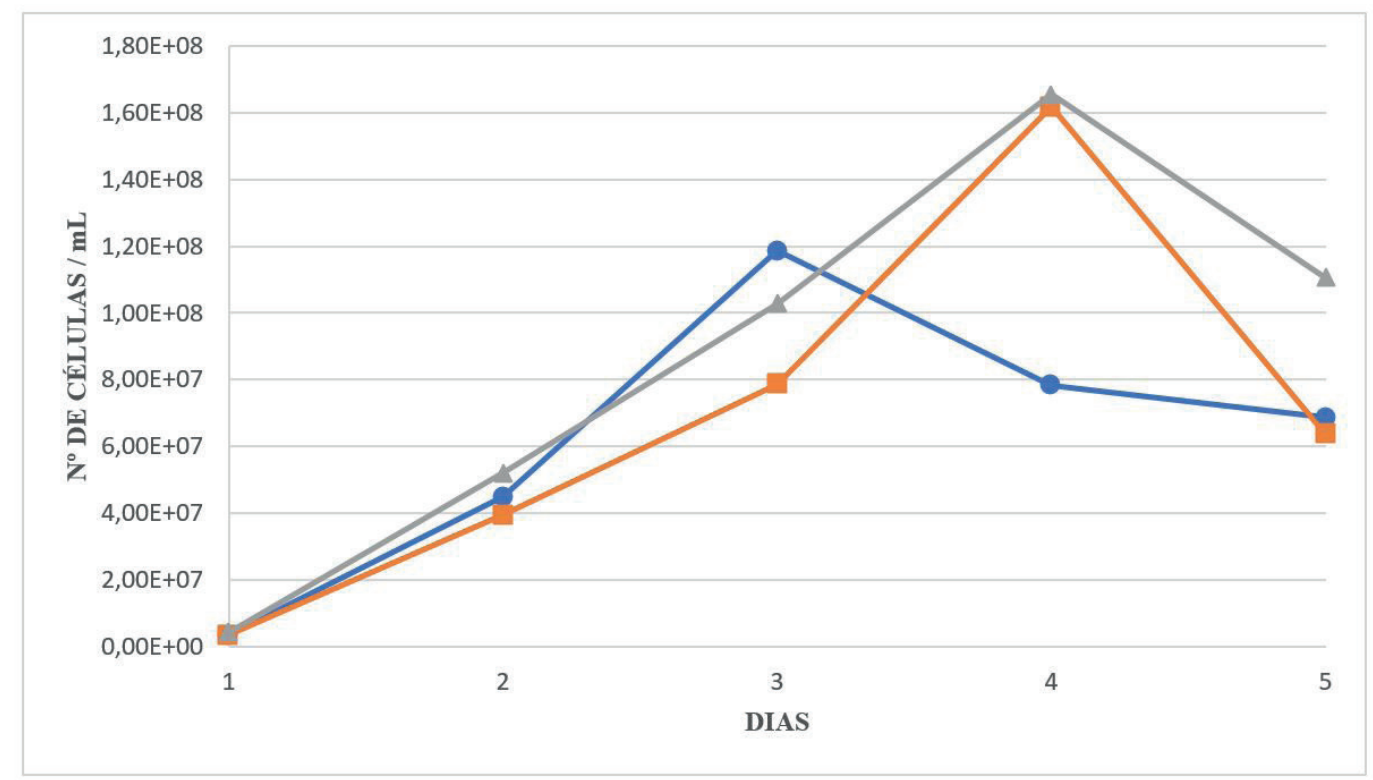

Fonte: os autores

Segundo Borzani et al. (2001), o crescimento microbiano em culturas líquidas é constituído por fases, sendo elas: fase de latência (lag), logarítmica ou exponencial (log), estacionária e, por último, de declínio ou lise.

O comportamento do crescimento celular presente no Gráfico 2 apresenta um deslocamento para a direita, o que, ao se correlacionar com as fases de crescimento, indica que as condições do meio alteradas pela adição de trub demandaram às células de levedura um maior tempo de adaptação ao meio, configurada pela fase lag, nos dias 2 e 3.

Sendo assim, a amostra padrão, ou seja, na qual não houve a introdução do trub, alcançou seu máximo desenvolvimento no terceiro dia de fermentação, em que obteve seu crescimento máximo de $1,18 \times 10^{8}$ células $/ \mathrm{mL}$. Nas amostras em que houve a adição do trub nas concentrações de $2 \mathrm{~g} / \mathrm{L} \mathrm{e} 4 \mathrm{~g} / \mathrm{L}$, observa-se um crescimento celular de $1,61 \times 10^{8}$ e $1,65 \times 10^{8}$, respectivamente, no quarto dia de fermentação, correspondendo a um aumento de $36 \%$ e $40 \%$, quando comparado ao controle. Kühbeck et al. (2007), em seu estudo sobre os efeitos do trub sobre a Saccharomyces cerevisiae, utilizou concentrações entre $0,5 \mathrm{~g} / \mathrm{L}$ e $4 \mathrm{~g} / \mathrm{L}$ e observou o mesmo efeito demonstrado pelo presente trabalho, tendo, para as concentrações em comum, obtido um aumento de $38 \%$ e $54 \%$ em relação ao crescimento celular.

Dessa forma, em relação ao crescimento celular, foi possível observar que a presença de trub aumentou o tempo da fase lag das células, mas, em compensação, houve uma maior produção de células, comparado com a cerveja controle. Além disso, o decréscimo de células em suspensão ao final da fermentação foi mais evidente na amostra com $2 \mathrm{~g} / \mathrm{L}$ do que na amostra com $4 \mathrm{~g} / \mathrm{L}$.

Em relação à viabilidade celular, a amostra apresentou valores iniciais de $69 \%, 88 \%$ e $67 \%$ e finais de $55 \%, 77 \%$ e $78 \%$, para as concentrações de 0,2 e $4 \mathrm{~g} / \mathrm{L}$, respectivamente. As amostras contendo trub, em relação ao controle, obtiveram comportamento opostos, pois os dados demonstram um decréscimo 
da viabilidade para a concentração de $2 \mathrm{~g} / \mathrm{L}$ similar ao controle. Por outro lado, houve um aumento na viabilidade para a concentração de $4 \mathrm{~g} / \mathrm{L}$, a qual, ao se relacionar ao crescimento celular, demonstra que, apesar do decaimento obtido para o último dia de análise, uma boa parte das células ainda se encontravam viáveis no meio.

O Gráfico 3 ilustra os dados demonstrados referentes ao teor alcoólico obtido durante os últimos 3 dias de fermentação, evidenciando o comportamento da análise.

Gráfico 3 - Valores de teor alcóolico presentes no mosto fermentado vs. tempo de fermentação para os últimos 3 dias para concentrações de trub de $0 \mathrm{~g} / \mathrm{L}(\bullet), 2 \mathrm{~g} / \mathrm{L}(\boldsymbol{\bullet})$ e $4 \mathrm{~g} / \mathrm{L}(\boldsymbol{\Delta})$. Teor inicial: 4,60\%, 4,65\% e 5,05\%; Teor final: 6,55\%, 6,70\% e 6,95\%; ABV teórico: 6,83\%.

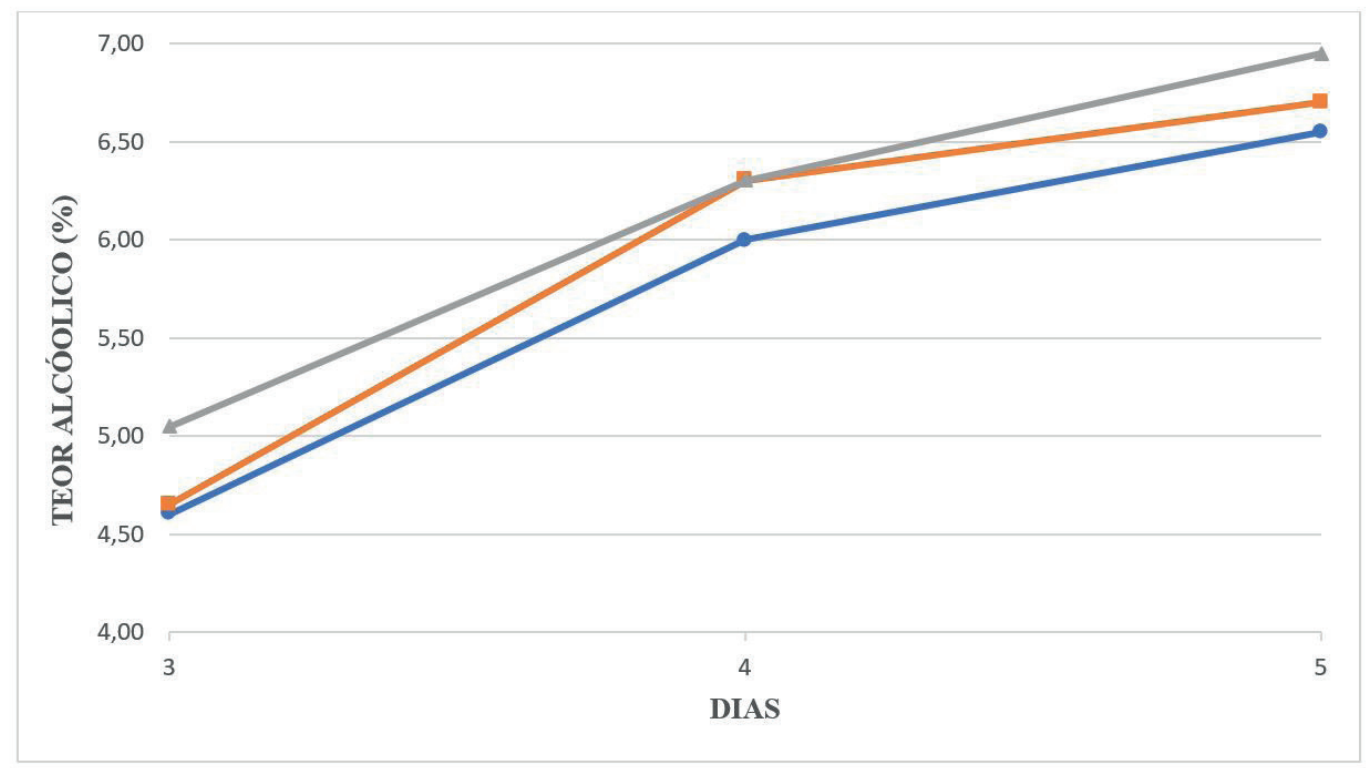

Fonte: os autores.

Tomando o expresso na análise, não se observa um aumento significativo em relação aos teores alcoólicos, porém o comportamento, apesar de similar, demonstra haver uma correlação entre o teor alcoólico e o aumento da concentração de trub. Tendo em vista que no decorrer do decaimento de extrato as concentrações obtiveram certa proporcionalidade entre os pontos de partida e final, pode-se atribuir um bom desempenho na fermentação quanto maior a concentração de trub, visto o aumento na formação de álcool.

Tendo sido obtido um ABV teórico de 6,83\%, a rota metabólica para a concentração de $4 \mathrm{~g} / \mathrm{L}$ obteve um teor alcoólico acima do esperado, sendo de 6,95\%, o que indica que tal concentração de trub foi eficiente para a formação de álcool, corroborando com a hipótese acima citada.

\section{CONCLUSÃO}

Diante das controvérsias em relação aos seus efeitos e sua remoção ser importante no processo de produção da cerveja, o trub aparenta não ser tão prejudicial quanto o indicado por estudos anteriores, pelo menos no que diz respeito ao decaimento de extrato e consequente produção de álcool, bem como em relação ao crescimento celular. 
Uma boa formação de álcool, como vista no presente trabalho, demonstra um bom desempenho das leveduras perante a fermentação, portanto, cabe um aprofundamento dos efeitos prejudiciais em relação a elas, bem como um acompanhamento, levando em consideração a introdução de maiores concentrações, a fim de se verificar o efeito contínuo do trub e uma possível dosagem de trub ótima, tendo em vista seu potencial eficaz na fermentação alcoólica, mas também para verificar se há algum dano à qualidade final da cerveja em relação as suas características organolépticas. Além disso, este estudo foi realizado em volumes pequenos, então, reproduções em larga escala são necessárias a fim de se confirmar os achados.

\section{REFERÊNCIAS}

BARCHET, R. Hot Trub: Formation and Removal. Brewing Techniques, v. 1, n. 4, 1993.

BORZANI, W.; SCHMIDELL, W.; LIMA, U. A. et al. Biotecnologia Industrial. São Paulo: Blucher, v. 1, 2001.

BRASIL. Decreto $n^{\circ}$ 9.902, de 8 de julho de 2019.Altera o Anexo ao Decreto $n^{\circ} 6.871$, de 4 de junho de 2009, que regulamenta a Lei $n^{\circ} 8.918$, de 14 de julho de 1994, que dispõe sobre a padronização, a classificação, o registro, a inspeção, a produção e a fiscalizaçã. Portal Oficial da Presidência da República do Brasil, 04 Junho 2019. Disponível em: <http://www.planalto.gov.br/ccivil_03/_Ato2019-2022/2019/ Decreto/D9902.htm\#art1>. Acesso em: 27 ago. 2019.

DAS NEVES, L. C. M. Obtenção da enzima glicose-6-fosfato desidrogenase utilizando Saccharomyces cerevisiae W303-181. Dissertação de Mestrado, Universidade de São Paulo. São Paulo. 2003.

GIORGI, V. D. V. \& JÚNIOR, J. D. O. C. A Produção Cervejeira como Patrimônio Intângivel. Cultura Histórica \& Patrimônio, v. 3, n. 2, p. 140-164, 2016.

GOMES, M. J. D. S. Acompanhamento da densidade do mosto durante a fermentação de cervejas produzidas em uma cervejaria artesanal. Trabalho de Conclusão de Curso. Universidade Federal Rural do Semi-árido. Mossoró, p. 1-38. 2018.

INSTITUTO ADOLF LUTZ , I.A.L. Normas Analíticas do Instituto Adolf Lutz, Métodos físicos e químicos para análises de alimentos. $4^{\circ}$ ed. São Paulo: [s.n.], v. 1, 2008.

KÜHBECK, F.; THIELE, F.; SCHÜTZ, M. et al. Influence of Lauter Turbidity and Hot Trub on Wort Composition, Fermentation, and Beer Quality. Journal of the American Society Brewing Chemists, v. 64, n. 1, p. 16-28, 2006.

KÜHBECK, F.; MÜLLER, M.; BACK, W. et al. Effect of hot trub and particle addition on fermentation perfomance of Saccharomyces cerevisiae. Enzyme and Microbial Technology, v. 41, p. 711-720, 2007.

LAURINTINO, T.N.S.; SOUZA, T.; JUNA, M. et al. Simulação da Etapa Fermentativa do Processo Cervejeiro. XXI Congresso Brasileiro de Engenharia Química. Fortaleza: [s.n.]. 2016.

MILAGRES, F. C. O. Desenvolvimento e caracterização de cerveja artesanal com umbu. Trabalho de Conclusão de Curso. Universidade Federal Rural de Pernambuco. Recife, p. 1-35. 2019.

PAPAZIAN, C. The complete joy of homebrewing. 3. ed. New York: HarperCollins Publichers Inc., 2003. 